\title{
CATALYTIC EPOXIDATION OF CYCLOHEXENE WITH TERT- BUTYLHYDROPEROXIDE USING AN IMMOBILIZED MOLYBDENUM CATALYST
}

\author{
S. Morales-delaRosa, J. M. Campos-Martin*, P. Terreros and J. L .G. Fierro \\ Sustainable Energy and Chemistry Group (EQS), Instituto de Catálisis y Petroleoquímica, \\ CSIC, C/Marie Curie 2, 28049 Madrid, Spain. http://www.icp.csic.es/eqsgroup/ \\ ${ }^{*}$ Corresponding author, e-mail: j.m.campos@icp.csic.es
}

\begin{abstract}
This work describes the synthesis of molybdenum complexes immobilized on a silica support and their performance in the epoxidation reaction of cyclohexene using tertbutylhydroperoxide (TBHP) as the oxidizing agent. The catalyst synthesis included solubilization of variable amounts of bis-oxomolybdenum (VI) acetylacetonate precursor in different solvents such as tetrahydrofuran (THF), ethanol, THF/water and ethanol/water mixtures and contact with the silica support. Characterization techniques demonstrated that the nature of the incorporated molybdenum species depends markedly on the solvent employed. If the solvent employed is an ethanol:water mixture, physical adsorption of the Mo-species onto the support surface occurs; however, when THF is used as the solvent (THF catalyst series), molybdenum is grafted on the silica surface via chemical bonding with the surface hydroxyl groups of silica. Specifically, these latter catalysts show similar performance to that of the homogeneous catalyst, although long-term experiments showed deactivation by leaching of the active phase.
\end{abstract}

\section{KEYWORDS}

Epoxidation, molybdenum, immobilized catalysts, and tertbutylhydroperoxide. 
Epoxides are a class of chemical compounds of great versatility in a wide variety of organic syntheses, which makes them particularly useful in the production of petrochemical compounds, fine chemicals and pharmaceuticals, among others [1]. One of the epoxides of greater importance in the chemical industry is propylene oxide, whose main application is the production of polyols, polyethers and polyesters, which when polymerized, create polyol polyethers which can be used as surfactants. It is also a critical reagent for the production of polyurethanes and can be obtained from the reaction of water with a variety of glycols as well as used in the production of unsaturated polyester resins.

The direct epoxidation of alkenes with molecular oxygen has been only successful with ethylene and butadiene, but an indirect route must be used for other alkenes. Many different methods have been developed for the preparation of epoxides, but the most extended technology is the epoxidation of alkenes with hydroperoxides in the presence of catalysts $[1,2]$. The active center of these catalysts is a transition metal in a high-oxidation state with Lewis acidity, such as: $\mathrm{Mo}(\mathrm{VI}), \mathrm{Ti}(\mathrm{IV}), \mathrm{V}(\mathrm{V})$ and $\mathrm{W}(\mathrm{VI})[2,3]$. The epoxidation reaction of alkenes occurs by the transfer of an oxygen atom from the alkylperoxometallic complex to the olefinic double bond $[4,5]$. It is well known that the selectivity to form an epoxide depends on several factors such as the ligand nature, the oxidation state or the Lewis acidity of the metal center [4,5]. At both industrial and laboratory scale, molybdenum-based homogeneous catalysts showed the highest performance in the epoxidation of alkenes with organic hydroperoxides [4].

There are many literature reports and patents describing the epoxidation of alkenes with $\mathrm{Ti}(\mathrm{IV})$-containing catalysts, including their implementation on an industrial scale [6]. However, much less is known about the performance of molybdenum catalysts for this reaction, as well as the ways to heterogenize molybdenum species on suitable supports. At present, there are no industrial processes based on heterogenized molybdenum catalysts owing to their poor stability and lack of sustained performance for long reaction times. Indeed, these disadvantages seriously limit their competitiveness with the homogeneous counterparts. Efforts to incorporate the Mo on several supports in different ways and checking their performance in the epoxidation of alkenes still continues. Various strategies have been reported to incorporate the active phase on organic polymers [7,8], zeolite [9], mesoporous silicas (MCM-41, SBA-15) [10-16] and active carbon [17]. Although these studies typically reported high conversion and selectivity, disadvantages such as high amounts of metal leaching, low reaction rates, low catalyst loadings, or limited accessibility to the reactants have often been reported. 
In line with the above, the present work was undertaken with the aim to investigate the incorporation of molybdenum to a silica gel support prepared with bis-oxomolybdenum(VI) acetylacetonate as precursor using different solvents and then tested in the epoxidation of cyclohexene using tert-butyl hydroperoxide (TBHP) as the oxidizing agent.

\section{EXPERIMENTAL}

\section{Catalysts Preparation}

The catalysts were prepared using a silica gel support (Silicycle F40). The synthesis of the catalysts was performed in a stirred tank reactor. The catalysts preparation was as follows silica $(0.1 \mathrm{~g} / \mathrm{mL})$ was added to the molybdenum precursor (bis(acetylacetonate)dioxomolybdenum(VI), Sigma-Aldrich) in the selected solvent. Then, the suspension was heated to reflux. The solids were filtered off, washed twice with the solvent, and dried at room temperature. Four solvents were employed in the synthesis: tetrahydrofuran (THF), ethanol, a THF/water mixture (1:1 by volume) and an ethanol/water mixture (1:1 by volume).

\section{Catalysts Characterization}

The molybdenum loading for each of the catalysts was determined by inductively coupled plasma optical emission spectrometry (ICP-OES) using a Perkin-Elmer Optima 3300 DV instrument.

Textural properties were evaluated from the adsorption-desorption isotherms of nitrogen recorded at $-196 \stackrel{\circ}{\circ} \mathrm{C}$ with a Micromeritics TriStar 3000 . The specific area was calculated by applying the BET method to the relative pressure $\left(\mathrm{P}^{\mathrm{P}} \mathrm{P}^{0}\right)$ range of the isotherms between 0.03 and 0.3 and taking a value of $0.162 \mathrm{~nm}^{2}$ for the cross-section of the adsorbed nitrogen molecule at $-196 \stackrel{\circ}{\circ}$. Pore-size distributions were computed by applying the BJH model to the desorption branch of the nitrogen isotherms.

UV-vis diffuse reflectance spectra measurements were performed with a Varian Cary 5000 UV-vis spectrophotometer equipped with an integrating sphere. $\mathrm{A} \mathrm{BaSO}_{4}$ sample was used as the reference. The samples were analyzed under ambient conditions. The reflection percentage was measured and presented as normalized Kubelka-Munk function.

Infrared spectra were recorded using a JASCO FT-IR 6300 spectrophotometer equipped with a TGS detector. Absorbance spectra were recorded in the $4000-350 \mathrm{~cm}^{-1}$ spectral region at a resolution of $4 \mathrm{~cm}^{-1}$. The samples were diluted in $\mathrm{KBr}$ to $1 \%$ by weight. Diffuse reflectance infrared Fourier transform spectroscopy (DRIFTS) was carried out on the same instrument equipped with an integration sphere and a Harrick HVC-DRP 
environmentally-controlled cell and MCT detector. The samples were analyzed without dilution.

X-ray diffraction profiles of the samples were recorded with an X'Pert Pro PANalytical diffractometer equipped with a $\mathrm{Cu}$ Ka radiation source $(\lambda=0.15418 \mathrm{~nm})$ and an $X^{\prime}$ Celerator detector based on real-time multiple strip (RTMS). The samples were ground and placed on a stainless steel plate. The diffraction profiles were recorded in steps over a range of Bragg angles $(2 \theta)$ between 4 and $90^{\circ}$ at a scanning rate of $0.02^{\circ}$ per step and at accumulation time of $50 \mathrm{sec}$. X-ray photoelectron spectra were recorded on a VG Escalab 200R spectrometer that was equipped with a hemispherical electron analyzer and a $\mathrm{Mg} \mathrm{K \alpha}(\mathrm{h} v=$ $1253.6 \mathrm{eV}) \mathrm{X}$-ray source (10 kV and $10 \mathrm{~mA})$. Charge effects on the samples were corrected by fixing the binding energy of the $\mathrm{C} 1 \mathrm{~s}$ peak of adventitious carbon at $284.8 \mathrm{eV}$. Atomic surface contents were estimated from the areas of the peaks and corrected using the corresponding sensitivity factors.

\section{Activity Test}

Catalytic epoxidation of cyclohexene with tert-butyl hydroperoxide (TBHP) was performed in a glass batch reactor, Mettler-Toledo Easy Max®. The reactor is equipped with a mechanical stirrer, a condenser and a septum for withdrawing samples. Catalysts were tested in the epoxidation of cyclohexene using two different reaction conditions. In the first one, severe reaction conditions were selected by utilizing equimolecular amounts of cyclohexene and TBHP. In a typical run, $16.6 \mathrm{~g}$ of cyclohexene and $12.0 \mathrm{~g}$ of a solution of TBHP in decane $(5 \mathrm{M})$ were mixed. The mixture was heated to the reaction temperature (65 $\left.{ }^{\circ} \mathrm{C}\right)$, and the catalyst was added (117 ppm Mo). In the second reaction conditions selected, the alkene/hydroperoxide ratio was fixed at 3:1, which is close to the one commonly used in industrial practice, that is working with an excess of alkene in order to maximize the epoxide production [2,3]. For this second reaction conditions, $8.35 \mathrm{~g}$ of cyclohexene were added to $16.77 \mathrm{~g}$ of a solution of TBHP in decane $(5 \mathrm{M})$ and $13.07 \mathrm{~g}$ of decane and $117 \mathrm{ppm}$ Mo, keeping constant the remaining reaction conditions. The TBHP concentration was measured by standard iodometric titration, and other organic compounds (cyclohexene, t-butanol, decane, epoxycyclohexane, 2-cyclohexenone, cis-1,2-cyclohexanediol and trans-1,2cyclohexanediol) were analyzed on a GC-FID Agilent 6850 device equipped with a HP-WAX capillary column $(30 \mathrm{~m} \times 0.53 \mathrm{~mm} \times 1 \mu \mathrm{m})[11,18]$. Although TBHP is detected by GC, this methodology cannot be used for quantification because of large error associated to peak shape.

Finally, the most promising candidate was tested in a continuous tubular reactor to analyze the stability of the catalyst. An X-Cube reactor (ThalesNano) working at atmospheric 
pressure, a total liquid flow of $0.4 \mathrm{~mL} / \mathrm{min}$, a weight ratio of 2.7:1:9.2 of cyclohexene:TBHP:decane mixture and a reaction temperature of $65^{\circ} \mathrm{C}$ were employed. The

Products selectivity was related to the TBHP converted according to the equation:

$$
S(\%)=100 *[\text { Product }] /\left([T B H P]_{0}-[\text { TBHP }]\right)
$$

where the subscript 0 stands for initial values, and all concentrations are expressed on a molar basis.

\section{RESULTS AND DISCUSSION}

Different samples were prepared by changing the solvent and the amount of molybdenum precursor in solution. Preliminary experiments allowed us to conclude that the type of solvent and the concentration of the molybdenum precursor in solution are the most important factors controlling the extent of the Mo loading. When the preparation is performed using ethanol as the solvent or a water:THF (1:1) mixture, the amount of Mo incorporated was very low $(<0.5 \mathrm{wt}$. \%) in both cases. Taking into account these discouraging results, no further attention was devoted to these samples. However, those catalysts prepared using water:ethanol (1:1) or THF as the solvent incorporate much larger amounts of molybdenum. Theese, some differences were noticed when using these two different solvents. In the case of the water:ethanol mixtures, both the color and aspect of the solution were found to change with time. At the beginning, the solution was clear and yellow turning, brown and opaque after a period of time. The recovered solids displayed a brown color while the filtrate was yellow. The results of chemical analysis indicated that this procedure yields an increase of molybdenum in the solid as more Mo precursor was added to the preparation (Table 1). A blank experiment without addition of the silica support showed the formation of a brown precipitate (BL-WE).

The behavior of samples prepared with THF was different: the color and aspect of the molybdenum solutions were quite similar for all preparations, remaining green. The solid recovered and the filtrated solution were both green. The chemical analysis data showed that the amount of molybdenum incorporated increases with the amount of precursor used in the synthesis reaching a plateau of approximately $7 \mathrm{wt}$. \% of molybdenum incorporation (Table 1). In the absence of the silica support (F40), no solid was formed.

Textural properties of the solids were revealed from the analysis of the $\mathrm{N}_{2}$ adsorptiondesorption isotherms. Commercial silica and catalyst samples display a type IV isotherm, according to the IUPAC' classification [19], with a hysteresis loop belonging to type $\mathrm{H} 2$ of the 
IUPAC classification. These isotherms are characteristic of mesoporous supports that contain narrow pores with access from wide pore bodies called "bottlenecks". The catalysts also showed a hysteresis loop located at relatively high pressures of the adsorbate. The BET surface area and pore volume decreased in all the catalysts with respect to the starting silica (F40) (Table 2). It was also observed that the amount of molybdenum incorporated on the support plays an important role and determine to a large extent adsorption capability. The catalysts prepared with THF (catalysts with a concentration of Mo around 5-7 wt. \%) show a small drop in both BET specific area and pore volume, and they remain constant regardless of the amount of molybdenum incorporated. Solids prepared with the water:ethanol mixture with high molybdenum loadings (WE3 and WE4) suffer an important decay of adsorption capability (Table 2).

Obtained solids were analyzed by X-ray diffraction (XRD). Depending on the solvent employed in the synthesis (Figure 1), significant differences were observed in the diffraction patterns of the samples. The silica support only exhibited a broad and low intense peak. Solids prepared with the water:ethanol mixture (samples WE) showed narrow peaks overlapping the silica background. No diffraction peaks were observed in the patterns of WE1 and WE2 samples (Figure 1a). However, intense peaks were observed in the patterns of WE3 and WE4 samples. The pattern of the brown solid obtained in absence of the support (sample WE-BL) was also recorded. After subtracting the silica background, WE3 and WE4 XRD patterns were identical to the WE-BL pattern (Figure 1a). The WE-BL diffraction pattern does not correspond to a single phase, rather it appears as a combination of oxides and hydroxides of molybdenum V and VI. Samples prepared using THF did not show any diffraction peak (Figure 1b), which indicates that the compounds obtained are amorphous or have a very small particle size.

UV-Vis spectra of the catalysts show the presence of four components: $200-300 \mathrm{~nm}$ tetrahedral Mo species, 300-400 nm absorption due to Mo octahedral, 400-600 nm polymeric molybdenum species, and a wide band that is characteristic of isolated compounds of $\mathrm{Mo}(\mathrm{V})$ at $700-900 \mathrm{~nm}$ [20]. Both, the nature of the solvent and the amount of molybdenum incorporated modify the coordination environment of Mo. WE catalysts (WE2, WE3, WE4) show the presence of octahedral molybdenum species, polymeric species and a weak signal for $\mathrm{Mo}(\mathrm{V})$ (Figure 2a). In the case of a low amount of molybdenum incorporated to silica support (WE1), the molybdenum is basically incorporated as isolated species in a tetrahedral coordination with the silica surface. Higher loading of molybdenum form a polymeric and tridimensional molybdenum species that have octahedral coordination. THF catalysts show the presence of Mo in both tetrahedral and octahedral coordination, although no polymeric molybdenum species are observed. However, a band attributed to isolated $\mathrm{Mo}(\mathrm{V})$ species, 
Samples prepared with the water:ethanol mixture were diluted in $\mathrm{KBr}$ and analyzed by FTIR (Figure 3). Bands of the silica support were recorded at $1300-1000 \mathrm{~cm}^{-1}, 801-806 \mathrm{~cm}^{-1}$ and 467-476 $\mathrm{cm}^{-1}$, which are attributed to different vibration modes of bulk silica, mainly symmetric stretching and bending modes of the bulk Si-O-Si bonds [21]. The band at ca. 970 $\mathrm{cm}^{-1}$ was attributed to the Si-OH stretching vibration of the surface silanol groups [20,21]. FTIR spectra of the WE series appear as a combination of the spectra of naked silica substrate and the blank sample (BL-WE) and differ from the corresponding spectrum of the molybdenum precursor $\left(\mathrm{MoO}_{2}(\mathrm{acac})_{2}\right)$ [22]. Peaks at 975,954 and $938 \mathrm{~cm}^{-1}$, which are attributed to $\mathrm{Mo}=\mathrm{O}$ symmetric and antisymmetric vibrations [22-24], can be detected. A very intense peak at $806 \mathrm{~cm}^{-1}$ is attributed to the Mo-O-Mo vibration [23,25], corresponding to the presence of polymeric Mo-O-Mo species as detected by UV-vis spectroscopy.

The signal due to molybdenum species in the THF series was very low. Therefore, DRIFTS was used instead of transmission FT-IR experiments (Figure 4). In addition to low intensity bands at 925 and $952 \mathrm{~cm}^{-1}$ present on the high loading Mo samples (THF3 and THF4), these DRIFT spectra were dominated by the signals due to species present on the support $\left(1300-1000,970,801-806 \mathrm{~cm}^{-1}\right)$. The low intensity bands were attributed to the $\mathrm{Mo}=\mathrm{O}$ symmetric and antisymmetric vibrations [26] (Figure 4a). A low intensity peak at 1350 $\mathrm{cm}^{-1}$, assigned to the deformation vibration of $\mathrm{CH}_{2}$ groups was also detected. In addition, the $-\mathrm{OH}$ stretching vibration region (Figure 4b) showed three signals, a sharp peak at $3700 \mathrm{~cm}^{-1}$ ascribed to the presence of terminal or geminal silanol groups, a second signal 3600-3650 $\mathrm{cm}^{-1}$ due to the vibration of $\mathrm{H}$-bonded hydroxyl groups, and a third signal at $3600-3500 \mathrm{~cm}^{-1}$ attributed to the vibration of internal silanol groups or perturbed $\mathrm{OH}$ groups due to contacts between particles [27]. The incorporation of Mo yields a clear reduction of the intensity of the bands at 3700 and $3600-3650 \mathrm{~cm}^{-1}$ that may be caused by the reaction of the hydroxyl groups with the Mo precursors (Figure 4b). Finally, two well-defined bands appear at 3000 and $2925 \mathrm{~cm}^{-1}$ due to the stretching vibration modes of the $\mathrm{C}-\mathrm{H}$ bonds in surface $-\mathrm{CH}_{3}$ groups formed during synthesis of the catalyst, suggesting that a part of the organic chain of the Mo precursor still remains in the sample (Figure $4 b$ ).

The XPS spectra of the samples (Figure 5) showed the characteristic spin-orbit coupling of Mo $3 d$ levels $\left(M_{0} 3 d_{5 / 2}\right.$ and $M o 3 d_{3 / 2}$ ). Two signals (Figure 5 ) can be discerned from the most intense Mo $3 d_{5 / 2}$ component of the Mo3d doublet: one at a low binding energy of $231.5 \mathrm{eV}$ that corresponds to $\mathrm{Mo}(\mathrm{V})$ species and the other at $232.5 \mathrm{eV}$ associated to species with a higher oxidation state Mo (VI) [28,29]. Samples prepared with THF present a very similar Mo3d spectra containing the two components mentioned previously. However, the spectra of the WE series change with the amount of Mo incorporated: Low amounts of molybdenum (WE1) leads to only $\mathrm{Mo}(\mathrm{VI})$ species, whereas the signal corresponding to 
1 molybdenum content (WE3 and WE4) results on only $\mathrm{Mo}(\mathrm{V})$ species being detected.

2 Additionally, identical Mo3d spectra were recorded for WE3 and WE4 samples and for the blank BL-WE sample.

Characterization data indicated that the nature of incorporated molybdenum species strongly depend on the solvent employed. When a mixture of ethanol:water is used (WE series), Mo is incorporated as a precipitated molybdenum compound on the silica surface, but when THF is used (THF series) molybdenum incorporation occurs by reaction between the molybdenum precursor and hydroxyl groups of the silica surface.

\section{Activity Tests}

The catalysts were tested in the epoxidation reaction of cyclohexene with TBHP. For comparison purposes, we used an homogeneous catalyst $\left(\mathrm{MoO}_{2}(\mathrm{acac})_{2}\right)$. For the first screening, we employed demanding reaction conditions, a cyclohexene:TBHP molar ratio of $1: 1$. For solid catalysts, we have introduced the same amount of molybdenum in the reaction by changing the solid amount depending on the amount of molybdenum incorporated onto the sample. The main product was cyclohexene epoxide, accompanied by very small amounts of 2-cyclohexen-1-ol and cys-1,2-cyclohexanediol. This low amount of allylic oxidation products could be attributed to the positive activity of BHT (2,6-bis(1,1dimethylethyl)-4-methylphenol) $(0.01 \%$ stabilizer of cyclohexene) that prevents the radical side-reactivity of the Mo catalyst. A blank experiment with naked silica was conducted and only decomposition of TBHP less than $5 \%$ was found to occur.

The conversion of the homogeneous catalyst seems to be limited to $\sim 80 \%$ peroxide conversion (Figure 6) although the epoxidation reaction is not limited by the equilibrium. This limitation is due to experimental constraints. Due to the exothermicity of the reaction, the addition of the homogeneous catalyst at $80^{\circ} \mathrm{C}$ (reaction temperature) leads to a sudden increase of temperature. The temperature inside the reactor can reach up to $100 \stackrel{\circ}{C}$ and a fraction of cyclohexene is lost since its boiling point is quite low $\left(83^{\circ} \mathrm{C}\right)$. The loss of cyclohexene was detected in the mass balance, but no loss of TBHP or t-butanol occured. This issue does not occur when working with heterogeneous catalysts in which the temperature spike is clearly lower.

The catalytic behavior depends clearly on the solvent employed in the preparation (Figure 6). All prepared samples are less active than the homogenous reference catalyst. Catalysts in the WE series have an induction period of approximately 15 min where no reaction happens, after which the TBHP conversion increases very slowly (Figure 6a). Results are similar to those obtained with the reference BL-WE catalyst. This induction period indicates a change in the catalyst structure induced by the reaction mixture. This 
effect was also observed in heterogeneous catalysts prepared with imidazolium polymers in presence of Mo-O-Mo [30,31]. WE catalysts characterization indicates the presence of this kind of molybdenum species. Samples in the THF series do not present any induction period and reach high conversion levels in a short period of time (Figure 6b). A deep analysis of the conversion curves indicates differences in the catalytic activity of the samples; the catalytic activity increases with the amount of molybdenum incorporated in the synthesis THF1 < THF2 $<$ THF3 $\approx$ THF4. Please note that the amount of molybdenum loaded is identical for all experiments. It seems that the presence of more hydrophilic surface (most likely -OH groups that have not reacted with molybdenum species in the preparation) reduces the catalytic activity of the catalyst. The selectivity for the epoxide product was similar for all catalysts tested and was approximately $85-86 \%$ with respect to the hydroperoxide. Selectivity levels lower than $0.8 \%$ was observed for organic products other than the epoxide derived from cyclohexene.

The excellent catalytic behavior of THF3 encouraged us to test the same catalyst in a more standard reaction condition using a molar ratio of 3:1 cyclohexene:TBHP, closer to that used in industry. For comparative purposes the homogeneous catalyst, $\mathrm{MoO}_{2}(\mathrm{acac})_{2}$, was also tested under the same conditions. Both catalysts are very active in the reaction, but they have slightly different conversion profiles. The heterogeneous catalyst (THF3) reaches higher conversion levels $(98 \%)$ at long reaction times (2h) whereas higher TBHP conversions are obtained at short reaction times. Regarding the epoxide selectivity, both catalysts have very high selectivity under these reaction conditions (epoxide selectivity is 93 $\%$ for the homogeneous catalyst and $97 \%$ for THF3). It can be noticed that the THF3 catalyst is a very good catalyst that can utilize the hydroperoxide (TBHP) almost quantitatively in the epoxidation of cyclohexene.

Finally, we studied the possible reuse of the catalyst [32], but the amount of catalyst added in the reaction is very small. Thus, it becomes impossible to recover and reuse the catalyst over several cycles. For this reason, we decided to study THF3 catalyst stability in a continuous flow reactor with a 3:1 molar ratio of cyclohexane:TBHP for $48 \mathrm{~h}$. The conversion profile (Figure 8) shows two different zones. At short reaction times, the conversion of TBHP is quite constant, but for long reaction times, it decreases from an initial $60 \%$ conversion to $20 \%$ after $24 \mathrm{~h}$ and is very low after $48 \mathrm{~h}$ of reaction. Usually, the stability of heterogeneous catalysts in liquid phase reaction is tested by reusing the catalysts after reaction. Since a typical epoxidation reaction takes $2 \mathrm{~h}$ in a batch reactor, a time on stream of $10 \mathrm{~h}$ is equivalent to carry out five reactions in batch. Consequently, if we had tested the stability with five reuses, we may claim that the catalyst do not deactivate, but actually in a long-term 
selectivity remains quite constant and quite high (>90\%) throughout the entire reaction period studied.

The used catalyst THF3 was recovered and analyzed by XPS and the molybdenum concentration was measured by ICP-OES. The amount of molybdenum present in the samples clearly decreased (Table 3), approximately ten times less, both in the bulk and surface analysis. The data suggest that the main part of the deactivation is due to leaching of the molybdenum from the catalyst surface. The distribution of surface $\mathrm{Mo}(\mathrm{VI})$ and $\mathrm{Mo}(\mathrm{V})$ species changes from the fresh to the used samples: most of the molybdenum remains as $\mathrm{Mo}(\mathrm{V})(\mathrm{BE}=231.3 \mathrm{eV})$ in the fresh sample, while most of the molybdenum is $\mathrm{Mo}(\mathrm{VI})(\mathrm{BE}=$ $232.8 \mathrm{eV}$ ) in the used sample. These data indicate two possible effects that are not mutually exclusive: (i) $\mathrm{Mo}(\mathrm{V})$ can be more easily leached from the surface of the catalyst, and (ii) part of the $\mathrm{Mo}(\mathrm{V})$ is oxidized under the reaction conditions [14].

\section{CONCLUSIONS}

We have studied the incorporation of molybdenum onto a silica gel support (F40) prepared with bis-oxomolybdenum(VI) acetylacetonate as the precursor using different solvents. The preparation in ethanol or a mixture THF:water (1:1) does not yield significant molybdenum incorporation, whereas the use of THF or a mixture of ethanol:water (1:1) yields the incorporation of molybdenum to the support. Characterization data indicated that the extent of molybdenum incorporation depends on the solvent employed. When a mixture of ethanol:water is used (WE series), the incorporation of Mo is produced by a precipitation of a molybdenum compound on the silica support, but when THF is used (THF series), the incorporation of molybdenum occurs by a reaction between the molybdenum precursor and the hydroxyl groups on the silica surface.

The heterogeneous catalysts are active in the epoxidation of cyclohexene with TBHP. However, the two catalyst series display different behavior. Catalysts prepared with THF are more active than the WE counterparts. The epoxide selectivity of the heterogeneous catalysts using a cyclohexene:TBHP $=1: 1$ (molar ratio) is similar for all heterogeneous catalysts and similar to the homogenous reference one. The catalytic behavior of THF3 catalyst is very good when employing an excess of alkene in the reaction (cyclohexene:TBHP = 3:1 molar ratio), yielding a high amount of epoxide.

The stability of the catalyst THF3 was also tested using a flow reactor. The catalyst was stable for a short time on stream. The reaction time corresponds to several reuses, but the catalyst suffers deactivation for longer times on stream. Molybdenum leaching was detected as well as an increase in the proportion of $\mathrm{Mo}(\mathrm{VI})$ species in the spent catalyst. 
2 [1] T. A. Nijhuis, M. Makkee, J. A. Moulijn and B. M. Weckhuysen (2006) The production of

3 propene oxide: Catalytic processes and recent developments. Industrial and Engineering

4 Chemistry Research 45(10):3447 -3459

5 [2] J. M. Kobe, W. E. Evans, R. L. June and M. F. Lemanski (2002)Epoxidation '

6 Industrial In: Encyclopedia of Catalysis John Wiley \& Sons, Inc.,

7 [3] M. L. Merlau, C. C. Borg-Breen and S. T. Nguyen (2002)Epoxidation ' Homogeneous

8 In: Encyclopedia of Catalysis John Wiley \& Sons, Inc.,

9 [4] R. A. Sheldon and J. A. Van Doorn (1973) Metal -catalyzed epoxidation of olefins with 10 organic hydroperoxides : I. A comparison of various metal catalysts. Journal of Catalysis $11 \quad 31(3): 427 \quad-437$

[5] R. A. Sheldon, J. A. Van Doorn, C. W. A. Schram and A. J. De Jong (1973) Metal 13 catalyzed epoxidation of olefins with organic hydroperoxides. II. The effect of solvent and 14 hydroperoxide structure. Journal of Catalysis 31(3):438 -443 Propylene epoxidation over titanium-on-silica catalyst | the heart of the SMPO process. Catalysis Today 93 ' 95(0):199 -204

[7] D. C. Sherrington (2000) Polymer-supported metal complex alkene epoxidation catalysts. Catalysis Today 57(1 -2):87 -104

[8] M. L. Mohammed, D. Patel, R. Mbeleck, D. Niyogi, D. C. Sherrington and B. Saha (2013) Optimisation of alkene epoxidation catalysed by polymer supported Mo(VI) complexes and application of artificial neural network for the prediction of catalytic performances. Applied Catalysis A: General 466(142 -152 cyclohexene: evidence from shape-selective poisoning. Journal of Molecular Catalysis 32(3):325 -332 
1 [10] J. Moreno, J. Iglesias, J. A. Melero and D. C. Sherrington (2011) Synthesis and

2 characterisation of (hydroxypropyl) -2-aminomethyl pyridine containing hybrid polymer-

3 silica SBA-15 materials supporting Mo(vi) centres and their use as heterogeneous

4 catalysts for oct-1-ene epoxidation. Journal of Materials Chemistry 21(18):6725 -6735

5 [11] L. Barrio, J. M. Campos-Martín, M. P. De Frutos and J. L. G. Fierro $\frown 2008 \smile$ Alkene 6 epoxidation with ethylbenzene hydroperoxides using molybdenum heterogeneous catalysts.

7 Industrial and Engineering Chemistry Research 47(21):8016 -8024

8 [12] J. Y. Piquemal, J. M. Manoli, P. Beaunier, A. Ensuque, P. Tougne, A. P. Legrand and J.

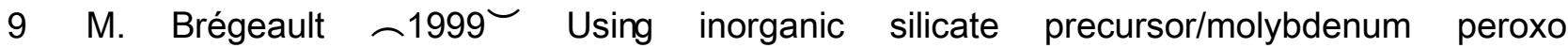
10 complexes/onium salt interfaces in aqueous acidic media to design mesoporous silica with 11 high molybdenum content and high dispersion. Microporous and Mesoporous Materials 12 29(3):291 -304

[13] P. Célestin Bakala, E. Briot, L. Salles and J. M. Brégeault $\frown 2006 \smile$ Comparison of 14 liquid-phase olefin epoxidation over MoOx inserted within mesoporous silica (MCM -41, SBA-15) and grafted onto silica. Applied Catalysis A: General 300(2):91 $\quad-99$ (2014) Molybdenum -MCM-41 silica as heterogeneous catalyst for olefin epoxidation. Journal of Molecular Catalysis A: Chemical 386(108 -113

[15] M. Bagherzadeh, M. Zare, T. Salemnoush, S. Özkar and S. Akbayrak (2014) Immobilization of dioxomolybdenum( $\mathrm{VI})$ complex bearing salicylidene 2 -picoloyl hydrazone on chloropropyl functionalized SBA-15: A highly active, selective and reusable catalyst in olefin epoxidation. Applied Catalysis A: General 475(55 -62

[16] P. D. Vaz and C. D. Nunes (2012) The versatility of immobilized mo complexes in organic transformations - epoxidation and metathesis reactions. Current Organic Chemistry 16(1):89 -114

[17] M. Masteri-Farahani and S. Abednatanzi (2014) Molybdenum complex te thered to the surface of activated carbon as a new recoverable catalyst for the epoxidation of olefins. Applied Catalysis A: General 478(211 -218 
1 [18] R. Martos Calvente, J. M. Campos-Martin and J. L. G. Fierro (2002) Effective

2 homogeneous molybdenum catalyst for linear terminal alkenes epoxidation with organic

3 hydroperoxide. Catalysis Communications 3(6):247 -251

4 [19] K. S. W. Sing;, D. H. Everet;, R. A. W. Haul;, L. Moscou;, R. A. Pieroti;, J. Rouquerol; 5 and T. Siemieniewska (1985) Reporting physisorption d ata for gas/solid siystems with 6 special reference to the determination of surface area and porosity. International union of 7 pure and aplied chemistry 57(4):603

8 [20] F. Adam and A. Iqbal (2011) Silica supported amorphous molybdenum catalysts 9 prepared via sol' gel method and its catalytic activity. Microporous and Mesoporous 10 Materials 141(119 -127

11 [21] M. C. Capel-Sanchez, J. M. Campos-Martin and J. L. G. Fierro (2003) Influence of 12 solvent in the synthesis steps of titanium-supported amorphous silica epoxidation catalysts. 13 Journal of Catalysis 217(1):195 -202

[22] B. Šoptrajanov, A. Nikolovski and I. Petrov $\frown 1968$ Infrared spectra of dioxobis(acetylacetonato) tungsten (VI) and dioxobis(acetylacetonato) molybdenum (VI). Spectrochimica Acta Part A: Molecular Spect roscopy 24(10):1617 -1621

[23] C. Rocchiccioli-Deltcheff, M. Fournier, R. Franck and R. Thouvenot (1983) Vibrational investigations of polyoxometalates. 2. Evidence for anion-anion interactions in molybdenum(VI) and tungsten(VI) compounds related to the Keg gin structure. Inorganic Chemistry 22(2):207 -216

[24] L. Seguin, M. Figlarz, R. Cavagnat and J. C. Lassègues $\frown 1995 \smile$ Infrared and Raman spectra of $\mathrm{MoO} 3$ molybdenum trioxides and $\mathrm{MoO} 3 \cdot \mathrm{xH}_{2} \mathrm{O}$ molybdenum trioxide hydrates. Spectrochimica Acta Part A: Molecular and Biomolecular Spectroscopy 51(8):1323 -1344

[25] M. Misono, N. Mizuno, K. Katamura, A. Kasai, Y. Konishi, K. Sakata, T. Okuhara and Y. 25 Yoneda (1982) Catalysis by Heteropoly Compounds. III. The Structure and Properties of 26 12-Heteropolyacids of Molybdenum and Tungsten (H3PMo12 -xWxO40) and Their Salts Pertinent to Heterogeneous Catalysis. Bulletin of the Chemical Society of Japan 55(2):400 - -406 
1 [26] G. M. S. El Shafei and M. M. Mokhtar (1995) Interaction between molybdena and 2 silica: FT-IR/PA studies of surface hydroxyl groups and pore structure assessment. Colloids

3 and Surfaces A: Physicochemical and Engineering Aspects 94(2 3):267 -277

4 [27] M. C. Capel-Sanchez, L. Barrio, J. M. Campos-Martin and J. L. G. Fierro (2004)

5 Silylation and surface properties of chemically grafted hydrophobic silica. Journal of Colloid

6 and Interface Science 277(1):146 -153

7 [28] S. Ikari, Y. Sasaki, A. Nagasawa, C. Kabuto and T. Ito (1989) A new mixed

8 molybdenum-tungsten dinuclear complex, bis $\sim \mu$-oxo $\frown$ ح-ethylenediaminetetraacetato-

$9 \quad \mathrm{~N}, \mathrm{~N}_{\text {_ }}$ )o xomolybdenum(V) oxotungstate(V). Inorganic Chemistry 28(7):1248 $\quad-1254$

10 [29] S. O. Grim and L. J. Matienzo (1975) X -Ray photoelectron spectroscopy of inorganic 11 and organometallic compounds of molybdenum. Inorganic Chemistry 14(5):1014 -1018

12 [30] D. C. Sherrington and S. Simpson (1991) Polymer -supported Mo and V cyclohexene 13 epoxidation catalysts: Activation, activity, and stability. Journal of Catalysis 131(1):115 14126

[31] D. C. Sherrington and S. Simpson (1993) Polymer -supported Mo alkene epoxidation 16 catalysts. Reactive Polymers 19(1 -2):13 -25

17 [32] R. A. Sheldon, M. Wallau, I. W. C. E. Arends and U. Schuchardt (1998) 18 Heterogeneous Catalysts for Liquid-Phase Oxidations: Philosophers' Stones or Trojan 19 Horses? Accounts of Chemical Research 31(8):485 - -493 
1 Table 1 Amount of molybdenum incorporated in the catalyst as a function of precursor concentration and the solvent

\begin{tabular}{|c|c|c|c|}
\hline Sample & Solvent & $\begin{array}{c}\text { Amount of Mo in solution } \\
\text { (g Mo/g silica) }\end{array}$ & wt. \% Mo \\
\hline THF1 & THF & 0.11 & 4.9 \\
\hline THF2 & THF & 0.22 & 5.5 \\
\hline THF3 & THF & 0.33 & 6.9 \\
\hline THF4 & THF & 0.45 & 7.0 \\
\hline WE1 & Water:Ethanol (1:1) & 0.11 & 0.2 \\
\hline WE2 & Water:Ethanol $(1: 1)$ & 0.22 & 7.6 \\
\hline WE3 & Water:Ethanol $(1: 1)$ & 0.33 & 15.2 \\
\hline WE4 & Water:Ethanol $(1: 1)$ & 0.45 & 19.0 \\
\hline
\end{tabular}

3

4

5 
3 Table 2 Pore size and BET specific area of different samples

\begin{tabular}{|c|c|c|}
\hline Sample & BET Specific area $\left(\mathrm{m}^{2} / \mathrm{g}\right)$ & Pore volume $(\mathrm{mL} / \mathrm{g})$ \\
\hline F40 & 470 & 0.60 \\
\hline THF-1 & 440 & 0.58 \\
\hline THF-2 & 434 & 0.54 \\
\hline THF-3 & 429 & 0.55 \\
\hline THF-4 & 427 & 0.53 \\
\hline WE-1 & 471 & 0.60 \\
\hline WE-2 & 430 & 0.54 \\
\hline WE-3 & 334 & 0.44 \\
\hline WE-4 & 281 & 0.38 \\
\hline
\end{tabular}

4

5 
2 Table 3 Molybdenum loading, binding energies (eV) of Mo3d core-levels and 3 surface atomic ratio of fresh and used catalyst THF3 in a flow reactor

\begin{tabular}{|c|c|c|c|}
\hline Sample & Mo3d $_{5 / 2}$ & Mo/Si at & Mo (wt. \%) \\
\hline THF3 Fresh & $\begin{array}{l}231.3(72) \\
232.9(28)\end{array}$ & 0.053 & 6.9 \\
\hline THF3 Used & $\begin{array}{l}231.3(24) \\
232.8(76)\end{array}$ & 0.006 & 0.6 \\
\hline
\end{tabular}

4

5 

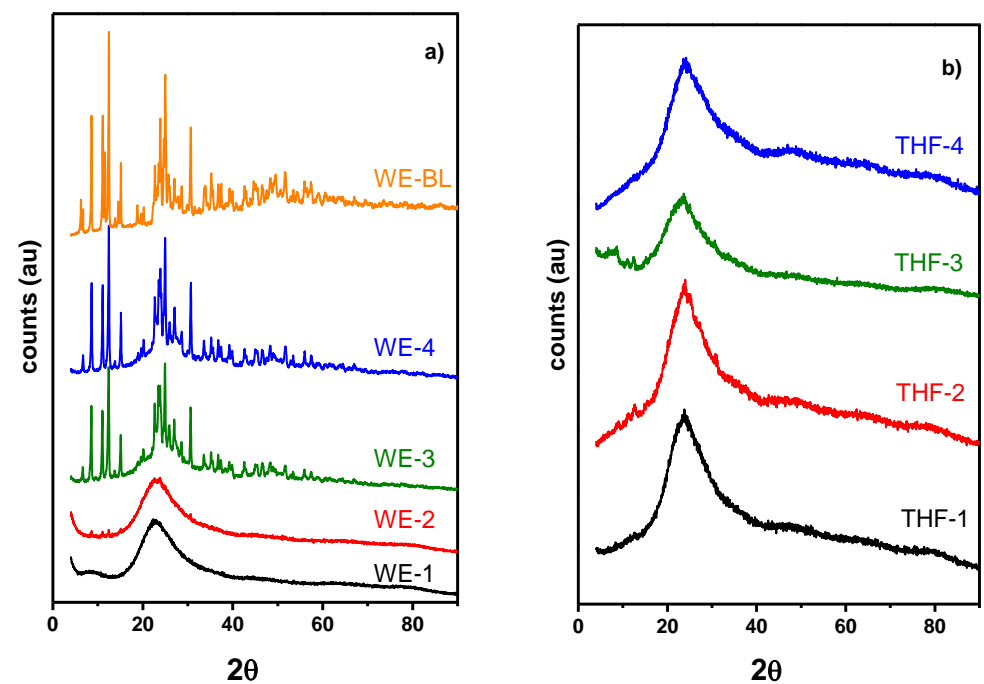

2 Figure 1 X-Ray diffraction patterns of catalysts prepared with different solvents. (a), synthesized with water:ethanol mixture = 1:1 (by volume); and (b), synthesized with THF. 

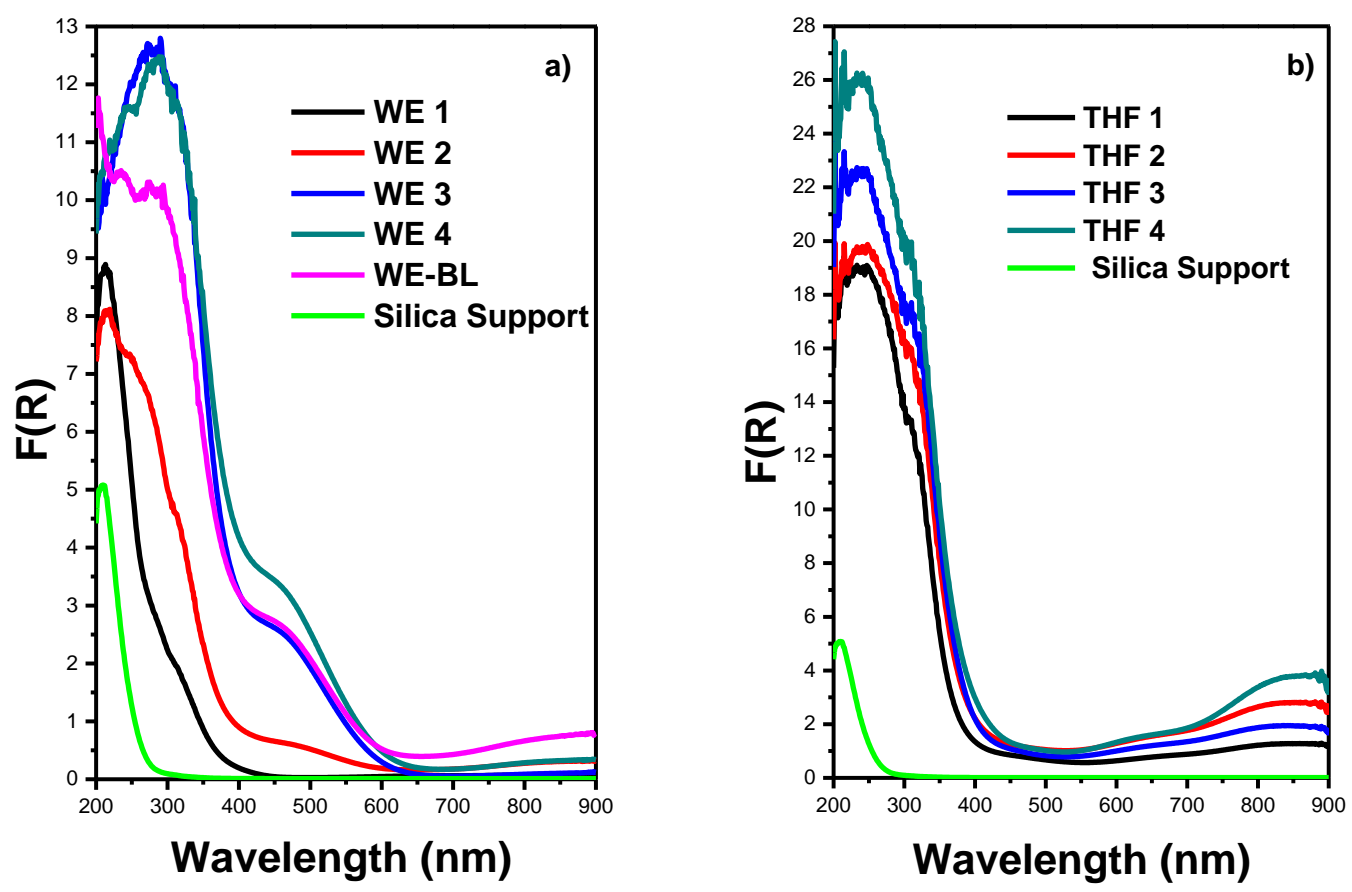

2

3 Figure 2 UV-Vis spectra of catalysts prepared with different solvents. (a), in 4 water:ethanol mixtures = 1:1 (by volume); and (b), Synthesized with THF and silica (Silicycle F40) support as reference. 


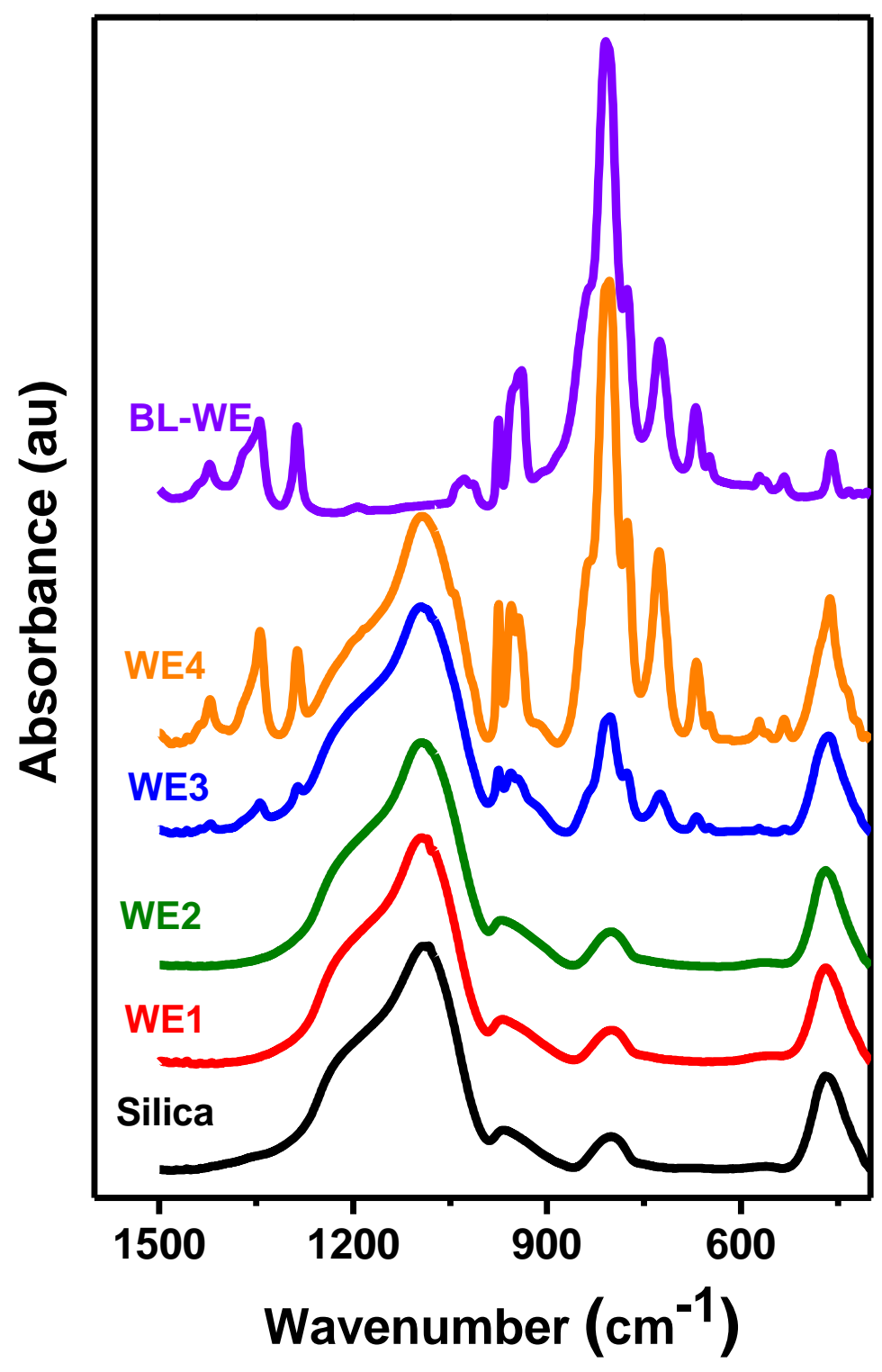

Figure 3 Transmission FT-IR spectra of catalysts prepared with water:ethanol = 1:1 (by volume). Samples were diluted in $\mathrm{KBr}$. 

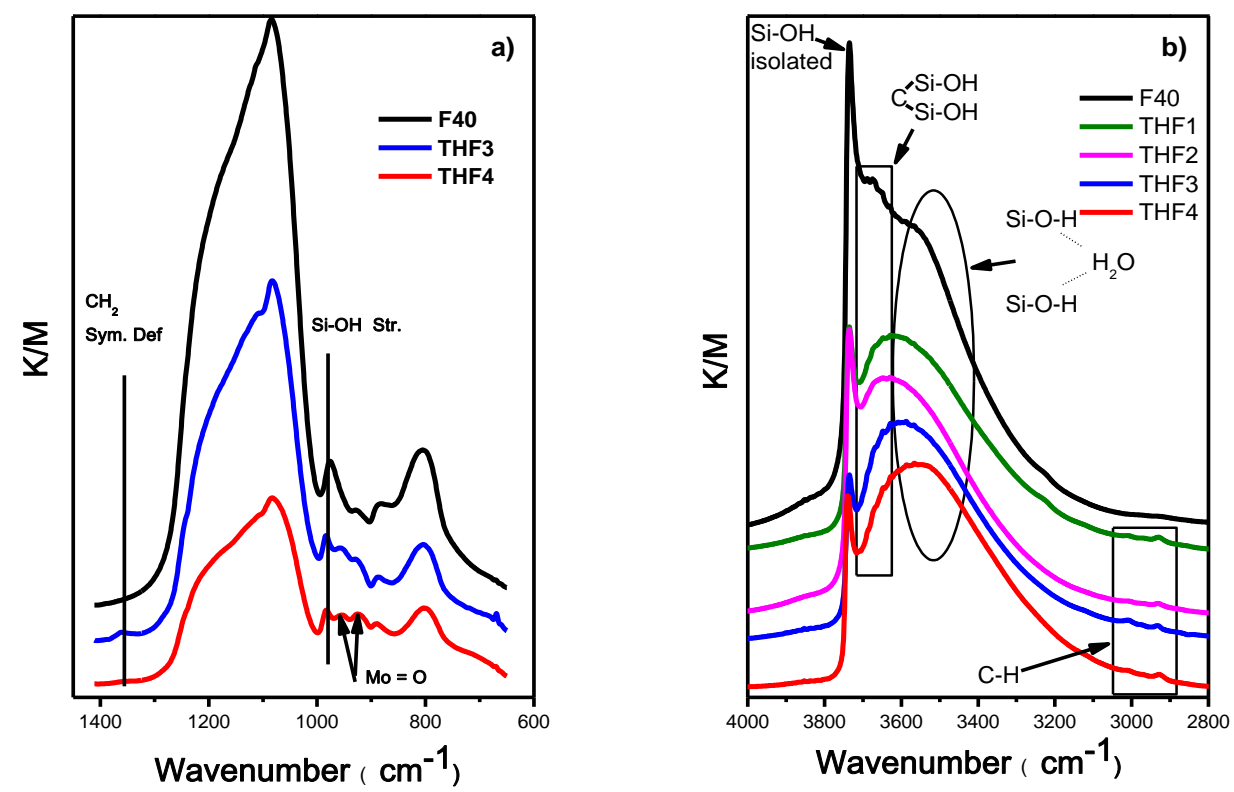

1

2 Figure 4 DRIFTS of catalysts prepared with THF and dried "in situ" at $200^{\circ} \mathrm{C}$ 3 under $\mathrm{He}$.

4 

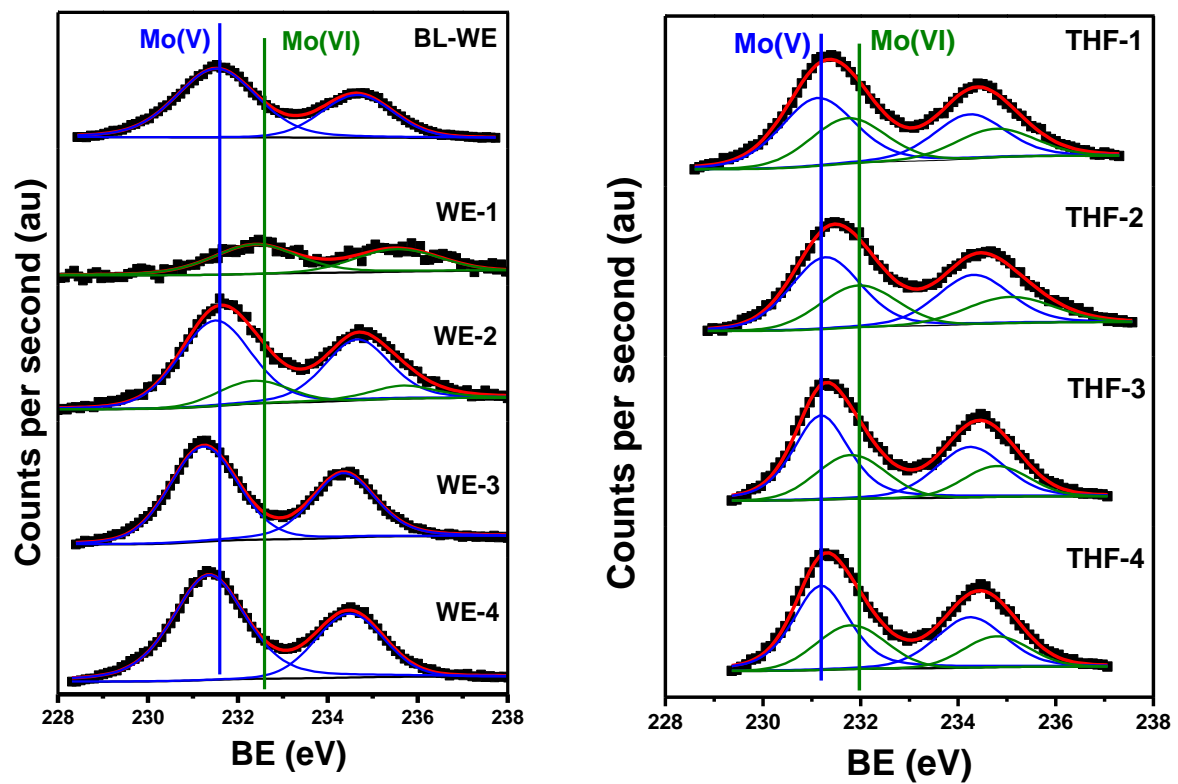

Figure 5

Mo 3d core-level energy regions of WE and THF catalysts series. (a), catalysts synthesized with water:ethanol = 1:1 (by volume); and (b), catalysts synthesized with THF. 

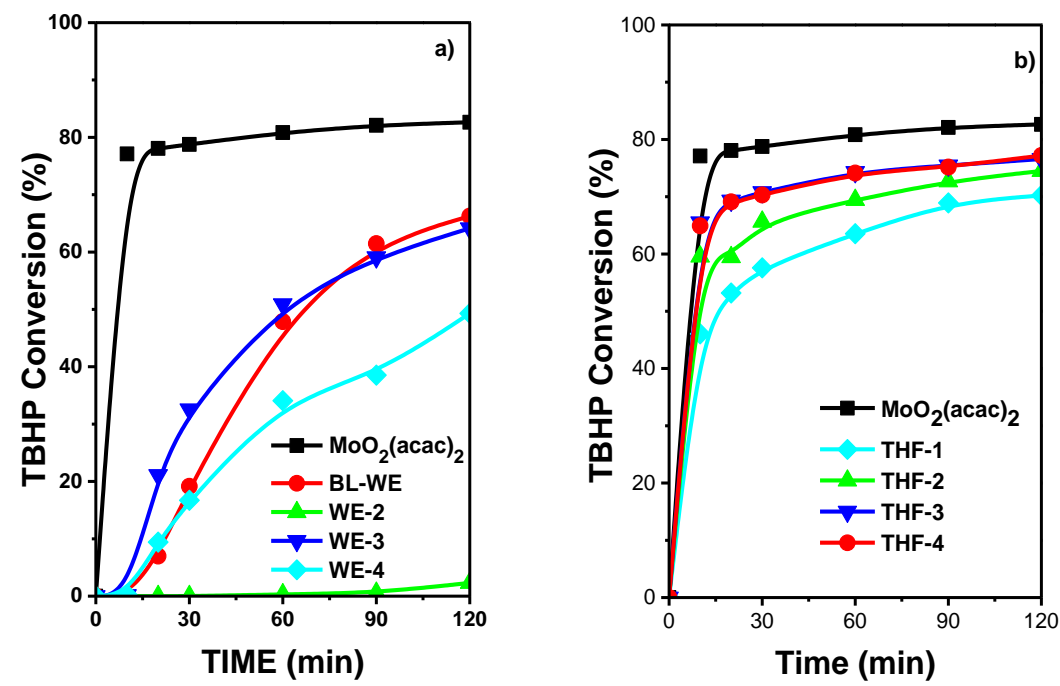

1

2 Figure 6 Activity tests of WE and THF catalyst series. (a), catalysts synthesized 3 with water:ethanol = 1:1 (by volume); and (b), catalysts synthesized with THF. Reaction conditions: cyclohexene:TBHP) = 1:1 (by volume). 


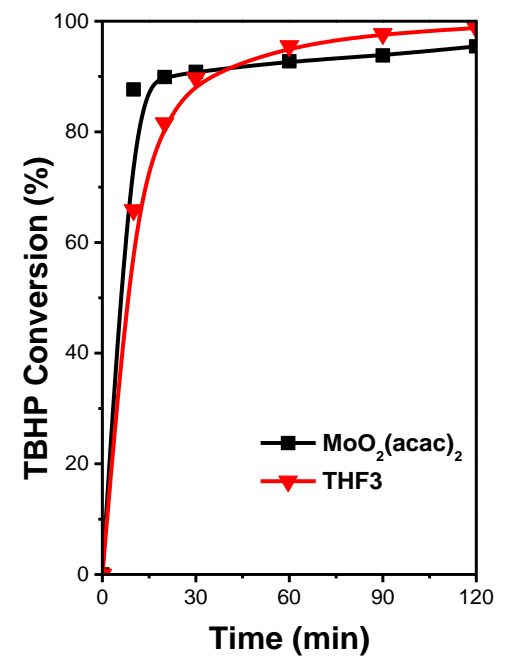

3 Figure 7 Activity test using THF3 and homogeneous $\mathrm{Mo}_{2}(\mathrm{acac})_{2}$ catalyst. Reaction conditions: cyclohexene:TBHP) = 3:1 (by volume).

5

6 


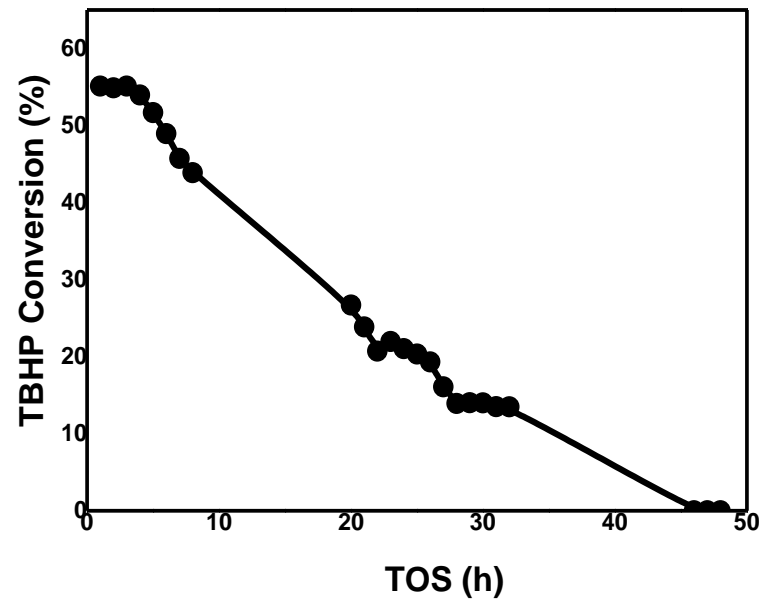

Figure 8 Continuous catalytic activity test of catalyst THF3.

3 